\title{
DISCUSSION OF "THE GOALS OF ANALYTIC THERAPY": SOME THOUGHTS ON KAREN HORNEY'S CONTRIBUTIONS
}

\section{Elissa P. Benedek}

It is hard to believe that 50 years have gone by since Karen Horney, M.D., founded the American Institute for Psychoanalysis and the Association for the Advancement of Psychoanalysis. Her contributions to the field of psychoanalysis and psychiatry in general have survived the test of time, forming a link between the old school of psychoanalytic thought and the move toward a biopsychosocial approach to the treatment of psychiatric patients.

Those who knew Karen Horney best found it difficult to account for her eagerness, creativity, indomitable spirit, originality, self-reliance, and strength in advancing her ideas in the face of professional opposition. Her daughter, Marianne Eckardt, stated,

"She was not one to worry about whether her thoughts would be right. She first thought her thoughts. She was always questioning and working and debating and discussing. And that went on throughout her life. She knew the inner satisfaction of thinking and debating. She was a beautiful lecturer. She always had notes, but she never read her lectures, and they always made a circle. She was at home in her own creative concepts."

Horney's creative concepts were expressed in a series of articles and books dedicated to the advancement of psychoanalysis and based on her own experiences in analytic work with patients and with herself. She stated, "Progress in psychoanalysis can only be made the hard way by including ourselves and our difficulties. If we remain static and adverse to change, our theories are bound to become barren and dogmatic."

No one would ever accuse Horney of forming theories that were "barren and dogmatic." Although she advanced the same ideas repeatedly, they were expanded, elaborated, refined, and illustrated eloquently with exam-

ELISSA P. BENEDEK, M.D., is Director, Training and Research, Center for Forensic Psychiatry, Ann Arbor, Ml, and Clinical Professor of Psychiatry, University of Michigan.

Address correspondence to: Center for Forensic Psychiatry, P.O. Box 2060, Ann Arbor, MI 48106. 
ples from her own life, her patients' lives, and literature. In particular, this 1951 paper-written the year before her death-is a concise reexamination of some of her most central concepts and reflects her clear, unpretentious writing style.

Horney's work brought new treatment techniques and helped close the distinction between analysis and therapy from which the field benefits today. Believing in the individuality of each person, she allowed patients to choose between the couch and face-to-face interaction during analysis. She also was flexible in negotiating treatment arrangements. Patients could see her once a week or every day as they collaborated with her. While she acknowledged the concepts of transference and countertransference-she was one of the earliest analysts to understand that feelings between the therapist and patient must be worked through—she held that patient and therapist stood on equal footing in the therapeutic alliance. Furthermore, such therapeutic agents as the analysts' presence, consistency, optimism, acceptance, lack of judgment, and sticking to the task were as important as dynamic interpretations.

In an analogy now more meaningful in light of psychiatry's move toward remedicalization in the past decade, Horney affirms in "The Goals of Analytic Therapy" that psychiatry is no different from other medical specialties. She said,

In other areas of medicine, the doctor is usually not contented with the removal of a symptom. He will hardly be satisfied to get rid of a cough without trying to cure its cause. Therefore, the objection that the personality is not the concern of analysis cannot really be sustained unless one clearly contends that the task of the doctor and the modern psychoanalytic therapy merely lies in achieving a symptomatic cure.

As 1 read this statement, I wished that those involved in managed care, the bugaboo of the 1990s and the nemesis of intensive psychoanalysis, would read Horney's work and respond to her ideas. As quoted above and throughout other writings, she emphasizes that the goal of analytic therapy is not simply to remove symptoms but rather to help patients understand their own neuroses so that they can reach a true understanding of who they are and eventually solve their problems themselves. It is impossible to define a time period in which this state can be achieved. Is a person crippled in a car accident given a time limit by which he must walk again or forfeit continued physical therapy? Why is less provided for those suffering from mental handicaps?

Since Horney's era, research has shown us that in terms of dollars and cents, attaining the therapeutic goal often translates into substantial savings in health care and recouped productivity because the somatic manifesta- 
tions of neurosis and psychological blockages to daily living are at the least ameliorated, if not eliminated.

In this paper, Horney also tackles the important concepts of patient education and behavior modification. Simply telling a patient what is wrong and instructing the patient to behave differently does not work, she reminds us:

If one treated a patient in this way, showed him outright where his illusions lay, and told him that he had to surrender them in order to be happy, he might say, if he was the more arrogant type, "I don't know. Are you crazy or am I?" There would even be some validity in this question, for if he really accepted what the doctor told him, he might break down immediately and fall into an abyss of selfcontempt.

To be lasting, Horney believed that change or symptoms removal must be based on an attitude change that permits self-assessment and the choice of personal values based on a knowledge of the real self.

Horney was a leader among her contemporaries - a special kind of leader who chose her own path. She had something important to say and knew it was important, but she never lapsed into producing anything false or ambiguous. In both her speaking and writing, she was simple and direct, appealingly lucid.

I'm sure she would not have liked to be called a feminist, but she was one of the field's first leaders to write about women and psychology and attack longstanding myths. Her early psychoanalytic work caused much controversy because of her refutation of Freud's ideas about feminine psychology. She did not believe that most women's psychics were shaped by penis envy or that masochism is a natural condition of women. She recognized that "normal" female behavior-dependence and submissivenesswas culturally, not genetically, determined. Of course, those revolutionary thoughts made her many enemies and few friends, but she stood by her ideas. And time has proven her right to do so.

May I add here that it was women like Horney-bold for their timewho helped make it easier for women like me to have a career in medicine and psychiatry. Nonetheless, one can't help but reflect on the fact that women are still in their adolescence as far as achieving parity with men in leadership positions. And while I am proud of the fact that I am the second woman to serve as the President of the American Psychiatric Association, it is shocking to realize that in an organization almost 150 years old there is not a long line of women who served in this capacity previously. Is it because of overt discrimination against women? Or is it because of other, subtle cultural factors? Whatever the cause, we need to follow Horney's example of strength in the face of opposition by looking at these issues and 
considering ways that each of us - regardless of any bias-can be assured of full participation in the career of our choice.

Horney's succinct definition of the goal of psychoanalysis in her 1939 book New Ways in Psychoanalysis is as relevant to that process as it is to any psychotherapy, and it is well that we remember it at a time when economic forces impinge upon us to apply only a Band-aid on wounds that won't stop bleeding: "The aim of analysis is not to render life devoid of risks and conflicts, but to enable an individual eventually to solve his problems himself. . . . [I]n short, to give him the courage to be himself." 